\title{
TELEMETERING kWh METER \\ MENGGUNAKAN KOMUNIKASI RADIO BERBASIS \\ MIKROKONTROLER AT89C2051
}

\author{
Oleh \\ Ketut Udy Ariawan \\ Jurusan Teknik Elektronika, FTK, Undiksha
}

\begin{abstract}
ABSTRAK
Pada penelitian ini dikembangkan prototype dari sistem kerja alat secara sederhana. Alat yang dibuat merupakan data loger, dimana data yang masuk ke Personal Computer (PC) sebagai tampilan layar merupakan pemakaian daya listrik (kWh-Meter).

Salah satu kriteria yang digunakan dalam perancangan alat adalah mikrokontroler AT89C2051 sebagai unit pengolahan data, modem sebagai pengubah sinyal digital ke sinyal sinusoidal atau sebaliknya, pemancar dan penerima FM yang bekerja pada frekuensi $433 \mathrm{MHz}$ sebagai media transmisi datanya.
\end{abstract}

Kata kunci : data loger, kWh-meter, mikrokontroler AT89C2051, modem.

\begin{abstract}
In this study developed a prototype of a working system in a simple tool. Tool that is made is a data loger, where data is entered into the personal computer (PC) as a display of electric power consumption (kWh-Meter).

One of the criteria used in the design tool is the AT89C2051 microcontroller as a data processing unit, modem as a digital signal converter for sinusoidal signals or vice versa FM transmitter and receiver that works at a frequency of $433 \mathrm{MHz}$ for data transmission medium.
\end{abstract}

Keywords : loger data, kWh-meter, microcontroller AT89C2051, modem.

\section{PENDAHULUAN}

Pengukuran jarak jauh atau telemetering umumnya dilakukan untuk kemudahan dan keamanan dimana pada kondisi tertentu, pengukuran secara langsung dapat membahayakan misalnya pengukuran tegangan tinggi atau gas beracun. Cara yang paling sederhana adalah dengan memperpanjang kabel probe atau sensor ke panel alat ukur, namun untuk jarak yang cukup jauh, hal ini menjadi 
tidak efisien karena harus memasang kabel yang panjang dan losses pada kabel semakin besar.

$\mathrm{kWh}$ adalah suatu peralatan yang digunakan untuk mengukur besarnya energi listrik yang dipakai, setiap bulan semua pelanggan listrik PLN harus membayar biaya pemakaian energi listrik yang dikonsumsi. Dalam hal ini biasanya energi listrik diperhitungkan dinyatakan dalam satuan kilo watt-jam atau kilo watthour disingkat $\mathrm{kWh}$ adalah energi yang dipakai oleh sebuah pesawat listrik yang besarnya 1 kilo watt selama 1 jam.

Atas permasalahan diatas, maka dibuat sistem telemetering dengan menggunakan komunikasi radio. Alat yang dibuat menggunakan gelombang VHF pada channel yang kosong agar tidak terjadi distorsi pada saat pengiriman data hasil pengukuran. Pada prinsipnya data analog diubah ke dalam format digital oleh sebuah ADC kemudian diproses oleh mikrokontroler untuk dipancarkan oleh alat komunikasi atau radio transceiver dimana data disalurkan ke radio transceiver melalui modem radio. Data yang dipancarkan kemudian diterima oleh penerima dan hasilnya dapat ditampilkan oleh sebuah PC.

\section{METODE}

Metode yang digunakan dalam perancangan dan realisasi telemetering daya PLN menggunakan komunikasi radio berbasis mikrokontroler AT89C51 adalah sebagai berikut:

- Mencari ide untuk menentukan alat apa yang akan dibuat. Dalam hal ini dikumpulkan sebanyak mungkin pilihan alat yang akan dibuat, selanjutnya menetapkan alat yang akan dibuat.

- Mengumpulkan data-data yang berhubungan dengan alat untuk direalisasikan.

- Melakukan pengujian terhadap fungsi alat tersebut dan dilihat apakah sesuai dengan yang diharapkan.

- Menarik kesimpulan secara keseluruhan dari hasil pembahasan dan pengujian. 
Secara garis besar dalam perancangan ini akan dibahas tentang pengukuran perancangan hingga realisasinya, yang meliputi:

- Pemilihan komponen.

- $\mathrm{kWh}$ meter.

- Rangkaian interface.

Perancangan ini mempunyai tujuan untuk merealisasikan hasil dari suatu ide yang berdasarkan pada teori yang telah dikaji sebelumnya, sehingga meghasilkan suatu model alat yang diharapkan dapat memiliki fungsi yang sesuai dengan spesifikasi yang telah ditentukan. Alat yang akan dirancang berfungsi untuk mengambil data analog dari kWh meter untuk selanjutnya ditampilkan dengan LCD. Data tersebut juga akan dikirim lagi ke PC untuk ditampilkan. Untuk mempermudah pelaksanaan perancangan, maka proses perancangan alat ini dibagi kedalam beberapa tahap, yaitu:

1. Menentukan spesifikasi alat.

2. Membuat diagram blok sistem yang akan direalisasikan.

3. Perancangan perangkat keras (hardware).

4. Pengukuran dan analisa.

\section{HASIL DAN PEMBAHASAN}

Seluruh bagian sistem dirancang agar memenuhi spesifikasi yang diharapkan sistem monitoring $\mathrm{kWh}$ ini diharapkan mempunyai spesifikasi sebagai berikut:

- Catu daya 5 VDC untuk catu daya alat.

- Power meter digunakan untuk pembaca daya.

- Pada prototype pembaca daya secara simulasi, dimana tegangan $0-3000$ $\mathrm{mV}$ diasumsikan 0 - 3000 watt.

- Menggunakan rangkaian sistem minimum mikrokontroler AT89C2051 untuk pengolahan data.

Diagram blok sistem ditentukan berdasarkan metode pemecahan yang dilakukan. Diagram blok sistem alat ini terlihat pada gambar dibawah ini: 


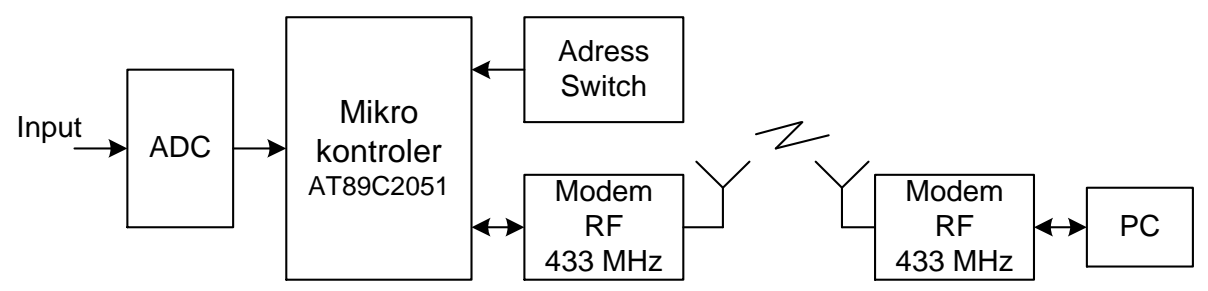

Gambar 1. Diagram Blok Sistem Perangkat Keras

Cara kerja:

Input analog berupa tegangan dari power meter dengan range $0-3$ VDC yang diasumsikan daya yang terukur 0 - 3000 watt akan masuk ke rangkaian ADC, dimana ADC yang dibuat menggunakan MAX127 yang mempunyai resolusi tinggi karena mempunyai lebar data 12 bit sehingga nilai 1 bit dikonversikan menjadi $3000 / 4096=0.7 \mathrm{mV}$ sehingga data $1 \mathrm{mV}$ akan terbaca dengan mudah. Data yang sudah berupa digital kemudian diolah oleh mikrokontroler AT89C2051 untuk dikirimkan ke PC melalui modem RF yang bekerja pada frekuensi $433 \mathrm{MHz}$. Address switch diperlukan sebagai data alamat yang dikirimkan karena alat pada prakteknya dibuat lebih dari 1 sesuai dengan jumlah pelanggan listrik. Dengan sistem ini maka proses monitoring pemakaian daya tidak manual namun secara elektrik dan wireless. Alat dapat diapliaksikan untuk monitoring pada gardu induk atau untuk monitoring disetiap pelanggan listrik sehingga tidak memerlukan pencatatan secara manual.

Pengujian alat diperlukan untuk mengetahui unjuk kerja dari alat yang sudah dibuat, dengan demikian dapat disimpulkan mengenai alat tersebut. Dalam pengujian alat, dilakukan terlebih dahulu pengukuran parameter yang diperlukan pada blok tertentu misalnya catu daya, simulasi kinerja, dan lain sebagainya.

\subsection{Pengukuran Catu Daya}

Catu daya yang digunakan pada alat sebesar 5 VDC dengan menggunakan IC regulator 7805 dengan kapasitas 1 ampere maksimum. Pada pengukuran tegangan keluaran terutama dianalisa kestabilan outputnya dengan tegangan input tertentu. Hasil pengukuran ditunjukkan pada tabel berikut : 
Tabel 1. Pengukuran Catu Daya 1

\begin{tabular}{|c|c|c|}
\hline Percobaan & Vin & Vout \\
\hline 1 & $4.5 \mathrm{VDC}$ & $4.2 \mathrm{VDC}$ \\
\hline 2 & $6 \mathrm{VDC}$ & $4.9 \mathrm{VDC}$ \\
\hline 3 & $9 \mathrm{VDC}$ & $5.01 \mathrm{VDC}$ \\
\hline 4 & $12 \mathrm{VDC}$ & $5.02 \mathrm{VDC}$ \\
\hline 5 & $24 \mathrm{VDC}$ & $5.01 \mathrm{VDC}$ \\
\hline
\end{tabular}

Analisa:

Vin adalah tegangan input ke IC 7805 (pin 1) yaitu tegangan hasil penyearahan, dan nampak bahwa agar IC 7805 bekerja dengan baik pada tegangan output stabil 5 VDC harus diberi Vin diatas 5 VDC. Hal ini sesuai dengan rekomendasi data sheet IC tersebut. Namun pada saat diberi Vin 24 VDC dan IC 7805 menjadi panas, artinya tegangan input terlalu besar.

Dengan hasil percobaan diatas akhirnya diputuskan tegangan input ditetapkan kurang dari 24 VDC. Tegangan sekunder AC diberikan pada 12 VAC dan setelah disearahkan menjadi sekitar 16.7 VDC dan berdasarkan percobaan berikutnya nampak bahwa tegangan output 5 VDC sangat stabil dan IC 7805 tidak panas.

Tabel 2. Pengukuran Catu Daya 2

\begin{tabular}{|c|c|c|}
\hline Percobaan & Vin & Vout \\
\hline 1 & $16.5 \mathrm{VDC}$ & $5.02 \mathrm{VDC}$ \\
\hline 2 & $16.9 \mathrm{VDC}$ & $5.01 \mathrm{VDC}$ \\
\hline 3 & $14.3 \mathrm{VDC}$ & $4.98 \mathrm{VDC}$ \\
\hline 4 & $14.7 \mathrm{VDC}$ & $4.96 \mathrm{VDC}$ \\
\hline 5 & $14.7 \mathrm{VDC}$ & $5.01 \mathrm{VDC}$ \\
\hline
\end{tabular}

Dari tabel tersebut terlihat bahwa Vout stabil berada disekitar 5 VDC, adapun perubahan sedikit masih dalam batas wajar karena IC 7805 mempunyai toleransi perubahan Vout sekitar 2\% atau $100 \mathrm{mV}$. Pada Vin terlihat jelas naik turun 
karena memang belum diregulasi sehingga tegangannya masih belum stabil terutama saat dihubungkan ke alat, nampak bahwa Vin turun drastis menjadi sekitar 14,7 VDC karena terbebani, namun pada Vout stabil. Hal ini menunjukkan bahwa rangkaian catu daya dengan menggunakan IC 7805 mempunyai kestabilan dan regulasi yang cukup baik.

\subsection{Pengukuran Rangkaian modul TX/RX}

Modul yang digunakan adalah TRLP 433 dengan frekuensi kerja $433 \mathrm{MHz}$ dan frekuensi input maksimum $2 \mathrm{KHz}$ karena mempunyai baud rate maksimum 1200 bps. Pengukuran dilakukan dengan frekuensi counter, namun karena frekuensi kerjanya cukup tinggi (433.92 MHz) sehingga pada input ditambah sebuah pembagi frekuensi (devider) dengan nilai bagi 10. Adapun pengecekan dilakukan dengan memberikan frekuensi gelombang kotak $1 \mathrm{KHz}$ dari generator pulsa pada pin $6 \mathrm{TX}$ modul kemudian diukur di RX pin 2 pada frekuensi counter tanpa devider.

Pada hasil pengujian terlihat bahwa frekuensi kerja yang terukur adalah 43.39 MHz, karena telah dibagi 10 sementara hasil transmisi frekuensi $1 \mathrm{KHz}$ diterima dengan baik di RX dengan demikian rangkaian modul TX/RX bekerja dengan baik

\subsection{Pengujian Alat}

Pengujian dilakukan secara menyeluruh dengan daya input simulasi $0-$ $3000 \mathrm{mV}$ dengan asumsi daya $0-3000$ Watt. Tegangan masukan simulasi ini diumpankan ke input ADC dan hasilnya dibaca di PC dengan program Pascal untuk menguji tingkat kesalahannya. Dari hasil pengujian ditunjukkan pada tabel berikut:

Tabel 3. Pengujian Alat

\begin{tabular}{|c|c|c|}
\hline Percobaan & Vin $(1 \mathrm{mV}=1$ Watt $)$ & Hasil Baca \\
\hline 1 & $1 \mathrm{mV}$ & $0 \mathrm{~W}$ \\
\hline 2 & $10 \mathrm{mV}$ & $10 \mathrm{~W}$ \\
\hline 3 & $100 \mathrm{mV}$ & $101 \mathrm{~W}$ \\
\hline 4 & $200 \mathrm{mV}$ & $205 \mathrm{~W}$ \\
\hline
\end{tabular}




\begin{tabular}{|c|c|c|}
\hline 5 & $300 \mathrm{mV}$ & $300 \mathrm{~W}$ \\
\hline 6 & $500 \mathrm{mV}$ & $500 \mathrm{~W}$ \\
\hline 7 & $1000 \mathrm{mV}$ & $1039 \mathrm{~W}$ \\
\hline 8 & $1250 \mathrm{mV}$ & $1247 \mathrm{~W}$ \\
\hline 9 & $2200 \mathrm{mV}$ & $2209 \mathrm{~W}$ \\
\hline 10 & $3000 \mathrm{mV}$ & $3020 \mathrm{~W}$ \\
\hline
\end{tabular}

Analisa:

Dari hasil percobaan terlihat bahwa saat diberikan umpan $1 \mathrm{mV}$ yang berarti 1 Watt pada PC tidak terbaca, hal ini karena memang resolusi ADC tidak mampu membaca yang kecil meskipun jika dihitung, dimana dengan lebar data 12 bit (4092) mempunyai resolusi $1 \mathrm{mV} / \mathrm{bit}$, hal ini dimungkinkan juga karena tegangan masukan $1 \mathrm{mV}$ tidak begitu stabil sehingga kadang-kadang terbaca dan ketidakstabilan tegangan input sangat berpengaruh pada percobaan selanjutnya dimana hasil baca tidak sesuai tegangan input namun tidak begitu jauh. Untuk pengujian yang lebih baik memang diperlukan sumber catu simulasi yang stabil dan baik dan alat ukur yang memadai.

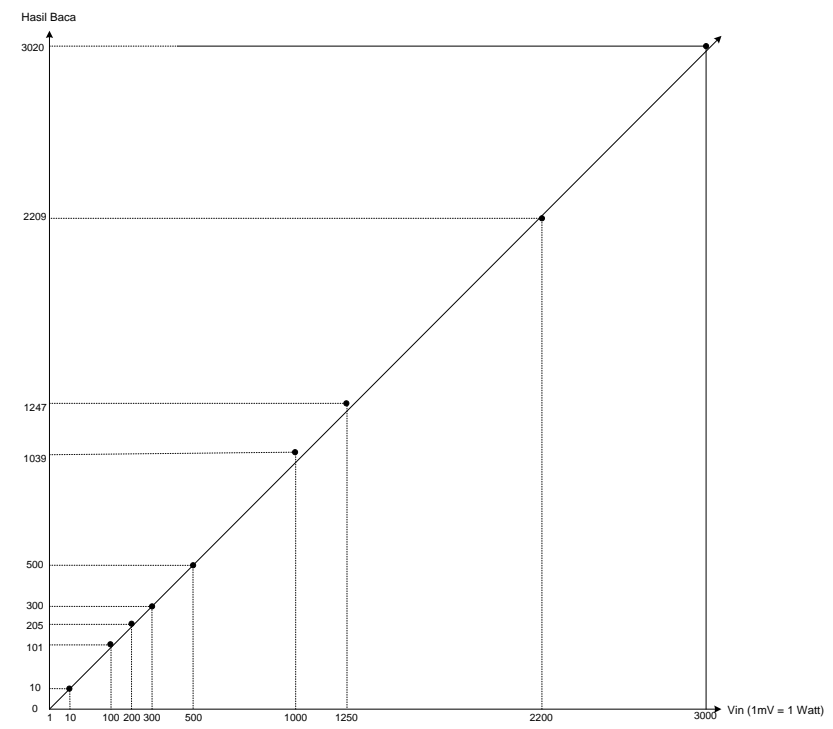

Gambar 2. Grafik Pengujian Alat 


\section{PENUTUP}

Dari hasil perancangan, pembahasan dan analisa maka dapat disimpulkan bahwa dengan memanfaatkan keunggulan teknologi mikrokontroler khususnya AT89C2051, alat akan dapat kita desain lebih sederhana serta mudah digunakan. Alat dapat memonitor range 0 - 3000 watt, dengan ADC 12 bit sehingga diharapkan mempunyai resolusi yang tinggi. Sistem transmisi wireless menggunakan frekuensi tinggi (433 MHz) agar menggunakan jalur kosong sehinggga data bisa sampai. Dengan resolusi 12 bit (4096) dan tegangan analog input $0-4,096$ Volt alat dapat membaca data $1 \mathrm{mV} / \mathrm{bit}$, sehingga asumsi $1 \mathrm{mV} /$ watt dapat diaplikasikan. Rangkaian ADC sangat berpengaruh terhadap spesifikasi sistem pembacaaan (resolusi).

Setelah pembuatan alat ini masih dirasakan banyak kekurangan, yaitu alat dapat dikembangkan dengan range yang lebih besar dengan cara lebar data ADC ditingkatkan, agar tidak mengubah resolusi. Karena alat dihubungkan dengan jaringan tegangan tinggi disarankan berhati-hati. Gunakan jalur frekuensi yang legal, sehingga tidak mengganggu frekuensi yang lain.

\section{DAFTAR PUSTAKA}

Bambang Anggoro, 1988, Alat-alat Ukur Listrik, ITB, Bandung.

DR. Soedjana Sapiie dan DR. Osamu Nishino, 2000, Pengukuran dan Alat-alat Ukur Listrik, Pradanya Paramitha.

H, Malvino, 1979, Prinsip-prinsip Elektronika, Edisi Kedua, Erlangga, Jakarta.

Intel. Inc MCS-51, 1986, User Manual Guide.

Modul Training, 2001, Mikrokontroler ATMEL 89C2051 Pelatihan AT89C2051.

Sutrisno, 1987, Elektronika Teori dan Penerapannya, ITB, Bandung.

JPTK, UNDIKSHA, Vol. 8, No. 2, Juli 2011 : 109 - 116 